\title{
A semântica formal das línguas naturais: histórias e desafios
}

Formal Semantics: stories and challenges

\author{
José Borges Neto \\ Universidade Federal do Paraná - UFPR \\ Ana Müller \\ Universidade de São Paulo - USP \\ Roberta Pires de Oliveira \\ Universidade Federal de Santa Catarina - UFSC
}

\section{Resumo}

Este artigo faz um resumo da história dos estudos semânticos no Brasil e no mundo, sobretudo das transformações iniciadas na década de 1970 e da abertura para uma semântica formal autônoma, que, hoje em dia, comporta diferentes visóes sobre a relação sintaxe e semântica, da centralidade da sintaxe ao isomorfismo sintaxe semântica. Mostramos como as ideias do lógico Richard Montague impulsionaram, através de Barbara Partee e Emmon Bach entre outros, tais estudos, estimulando o surgimento de novas vertentes, e como essas novas tendências foram inseridas no Brasil pela Unicamp com a ajuda de pesquisadores como Marcelo Dascal, Rodolfo Ilari e Carlos Franchi. O artigo inicia com uma breve descrição do que é a semântica formal, diferenciando-a de outras semânticas e, principalmente, da semântica lógica, praticada pelos filósofos, cujo objetivo é descrever raciocínios válidos. A semântica formal é uma ciência empírica que busca explicar o conhecimento semântico que um falante tem - sua capacidade de relacionar linguagem a algo que não é linguagem (mundos, modelos, conceitos), a composicionalidade 
e relações sistemáticas entre sentenças - através de uma metalinguagem lógico-matemática. Esse empreendimento tem sido bem sucedido, se expandindo para além da semântica em direção a uma maior interação com a pragmática formal. As tendências atuais são de interação com outras disciplinas - a psicolinguística, por exemplo - e a preocupação com línguas pouco descritas, como as línguas indígenas brasileiras. No Brasil, a semântica formal ganhou impulso com a criação dos workshops e tem conseguido um espaço cada vez mais significativo na linguística nacional e internacional.

\section{Palavras-chave}

Semântica, Semântica formal, História da Linguística, Estado da Arte.

\section{Abstract}

This paper reviews the history of the semantic studies in Brazil and worldwide, more specifically, the transformations that took place in the 1970s and the birth of an autonomous formal semantics which encompasses different visions of the relationship between semantics and syntax, from the centrality of syntax to the isomorphism of syntax and semantics. This paper also shows how the ideas of logician Richard Montague gave birth to the field, mainly through the studies of Barbara Partee and Emmon Bach and others. The paper also shows how these ideas were brought to Brazil, in particular to Unicamp, with the significant participation of researchers such as Marcelo Dascal, Rodolfo Ilari and Carlos Franchi. The paper starts with a brief description of what formal semantics is, differentiating it from other semantic theories and, more specifically, from logical semantics, which is carried out by philosophers, and of which main goal is to describe how valid a statement is. Formal semantics is an empirical science which aims at explaining the semantic knowledge speakers have and their ability to relate language to something which is not language itself (world views, models, concepts) the compositional elements of language, as well as the systematic relationship among 
sentences by means of a mathematical logical metalanguage. This enterprise has been successful, since formal semantics has also expanded its boundaries towards an interaction with formal pragmatics. Current studies in the field also show great interaction with other areas, such as psycholinguistics, and a concern with under-described languages, for instance, the Brazilian indigenous languages. In Brazil, Formal Semantics has had an upswing with the organization of conferences and workshops in the area and it has also gained the attention of national and international linguists.

\section{Keywords}

Semantics, Formal Semantics, History of Linguistics, State of the Art. 


\section{A}

semântica das línguas naturais é um empreendimento científico, um projeto coletivo que visa entender o fato de que nós, humanos, temos adota uma metalinguagem lógico-matemática. Se as línguas humanas são efetivamente semelhantes às linguagens lógicas é um ponto de divergentes opiniōes. Noam Chomsky (1955, 1980, 1982, 1990), por exemplo, já manifestou seu ceticismo várias vezes.

A década de 1970 vivenciou uma mudança na maneira de enxergar o objeto de estudos da semântica, que permitiu o estabelecimento de uma nova agenda de estudos e, com isso, uma superação de algumas disputas "metafísicas" que caracterizavam a visão tradicional da semântica. É a história dessa mudança e abertura para uma Semântica Formal autônoma, que este artigo procura alcançar. No Brasil, essa história só pode ser contada se passarmos por Rodolfo Ilari, Marcelo Dascal e Carlos Franchi, que na década de 70 estavam formando o Instituto de Estudos da Linguagem (IEL) e o currículo da graduação em Linguística da Unicamp. Os autores do presente texto são a segunda geração, exalunos do IEL, ex-alunos do Ilari, do Franchi, de ambos.

Em 2012, a Semântica Formal vive um momento de efervescência; há, como diz Barbara Partee (2011), um tanto que já aprendemos e estamos nos aventurando por vários caminhos. A Semântica Formal feita no Brasil de hoje começa a se inserir internacionalmente. Em 2012, no Brasil, duas conferências internacionais serão realizadas em torno da semântica e, hoje, existem semanticistas formais em instituições distintas como UESPI, UFRJ, USP, UFPR, UFSC e UFRGS, entre outras. Essa é, pois, uma história de desafios e conquistas.

É muito difícil, se não impossível, contar em poucas páginas essa história, porque é também uma história de avanços técnicos, na "maquinaria" desenvolvida. Os sistemas lógicos que utilizamos atualmente na semântica formal são muito sofisticados e muito poderosos. No entanto, para um semanticista 
formal das línguas naturais, o que importa é o dado empírico, o que os falantes produzem e o que eles deixam de produzir ou de interpretar, o dado negativo introduzido por Chomsky (PIRES DE OLIVEIRA, 2010). Somos guiados por o que é possível na semântica de uma língua e por o que não ocorre porque não faz parte de sua semântica, pelo sistema de uma língua e por esse sistema em relação a outras línguas.

\section{Introdução: as muitas semânticas}

Até a década de 70 e, muitas vezes ainda hoje, caracteriza-se a semântica como o estudo do significado. Essa definição levou a uma multiplicidade de abordagens, o que a torna muito pouco esclarecedora. Em primeiro lugar, porque os significados não são "coisas" que podemos pegar, medir ou observar com os sentidos. Como qualquer aluno de Letras constata rapidamente, existem diferentes concepções do que seja o significado e, em consequência, do que consiste estudá-lo. Em segundo lugar, porque o significado perpassa as diferentes formas de delimitar o objeto de estudos (o "lugar" em que se investigam, de início, os significados estão no morfema, na palavra, na sentença, no discurso ou no texto) e há muitas formas alternativas de estudar o objeto delimitado.

Há quem veja o significado como um valor em uma rede conceptual, como a semântica que se desenvolveu no interior do estruturalismo europeu (saussuriano). Uma semântica que adote essa concepção de significado vai tratar, fundamentalmente, do significado de morfemas ou palavras e, coerentemente, vai estudar prioritariamente os campos lexicais, daí partindo para outras estruturas ou níveis de articulação linguísticos. Há quem prefira entender o significado como uma entidade de natureza mental, uma representação interna, um "conceito". Essa concepção de significado permite várias formas de abordagem, todas elas compartilhando a busca sistemática do estabelecimento de relações entre o significado, sempre entendido como uma representação mental, e outros aspectos das línguas ou dos contextos culturais em que as línguas se inserem. Há ainda quem entenda o significado das expressóes linguísticas como o resultado do uso da língua, delimitado e determinado por condiçōes sociais. Também podemos encontrar abordagens que tomam as enunciações (e não os enunciados) como unidades de significado. Para essas semânticas da enunciação, uma expressão linguística só adquire, 
verdadeiramente, significado quando enunciada por um falante específico num contexto também específico.

Todas essas formas de estudar o significado são possíveis e cada uma delas apresenta vantagens e desvantagens. Evidentemente, existe uma afinidade entre a eleição de certos objetos, de certas formas de abordagem e certos paradigmas teóricos mais gerais. Uma teoria fundada em relaçôes sintáticas entre constituintes de sentenças, por exemplo, pode priorizar uma semântica que tome morfemas, palavras ou sentenças como espaço de observação dos significados. Uma teoria fundada nas enunciações tem nos proferimentos contextualizados sua unidade básica e o estudo dos significados das enunciaçôes envolve prestarmos atenção às intençóes dos falantes e aos contextos de uso.

Uma maneira alternativa de definir a semântica é identificar sua agenda de estudos. Não se trata de entender o significado - essa é uma noção muito vaga e difícil de ser explicitada -, mas de descrever e explicar uma capacidade que os falantes de qualquer língua têm e que podemos observar empiricamente: sua capacidade de compreender qualquer sentença da sua língua. Essa capacidade de interpretar pode ser apreendida pela observação das interaçóes linguísticas que um falante entretém que, inclui, entre outros o conhecimento de que certas sequências não são possíveis. Por exemplo, um falante sabe que podemos dizer algum menino, mas não podemos dizer algum o menino, não porque não podemos ter a sequência 'quantificador + artigo definido + nome' como em todo o colégio ou todos os meninos, mas por causa da semântica e da sintaxe dessas expressões. Precisamos explicar passo a passo, por exemplo, como produzimos todo $+o+$ Nome e como obtemos um significado dessa combinação e também porque não combinamos algum $+o+$ Nome.

A semântica formal é, assim, uma ciência empírica, com caráter preditivo. O objeto de estudos da semântica é, então, explicitar a capacidade que os falantes de uma língua têm, independentemente de eles irem ou não à escola, de atribuir significados ao que eles dizem e ao que lhes é dito (CHIERCHIA, 2003, tem essa visão). E as perguntas passam a ser, então: como é essa capacidade? Que propriedades ela tem? Como construir um modelo que a replique para a semântica? Essa é a agenda atual da semântica formal. Essa postura tornou-se possível a partir dos trabalhos de Chomsky e é o ponto de partida da semântica formal das línguas naturais, que tem em sua fundação a figura de Barbara Partee (ver 1969, 1970, 1973 e 1975). 
A semântica formal toma a "sentença" como sua principal unidade de análise, entre outras coisas, porque se um falante sabe uma língua, ele sabe em que condiçōes uma dada sentença é verdadeira. Ele sabe dividir as situações ("o mundo") em duas partes, uma em que a sentença é falsa e outra em que é verdadeira. Qualquer falante que sabe português sabe dizer quando a sentença está chovendo é ou seria verdadeira. Logo, ele sabe relacionar linguagem e mundo. Note-se que se ele sabe isso, escolher a sentença como unidade de análise passa a ser razoável, porque é a sentença que pode ser julgada verdadeira ou falsa. Notese também que explicar essa capacidade é agora independente da filiação metafísica quanto ao significado; tanto faz se o significado é uma entidade mental ou se é dado pelo uso, o que precisamos explicar é como um falante sabe o que ele sabe e se ele sabe relacionar uma cadeia sonora a um estado de coisas no mundo.

Antes de seguir adiante, talvez seja prudente aprofundar um pouco mais o que dissemos acima. Saber as condiçôes de verdade de uma sentença não é o mesmo que saber se a sentença é verdadeira ou não. Se olharmos para um gramado, não saberemos se o número de folhas de grama é par ou ímpar e, portanto, não saberemos se a sentença $O$ número de folhas de grama é par é verdadeira ou falsa. Por outro lado, como falantes de português, sabemos em que condiçōes essa sentença seria verdadeira: se o número de folhas de grama for par. Para chegarmos à verdade ou falsidade da sentença precisaríamos contar as folhas (e não cremos que alguém tivesse paciência para tanto). $\mathrm{O}$ tratamento semântico das sentenças, portanto, não se dá em termos de verdadeiro ou falso, mas de condiçôes de verdade. $\mathrm{O}$ falante que interpreta uma sentença não precisa saber se a sentença é verdadeira ou não, mas certamente sabe como o mundo deveria ser para que a sentença fosse verdadeira.

Da mesma forma, se um falante só souber o que significa (es)tá choven(d)o quando há um evento de chuva ocorrendo no momento do proferimento da sentença, ou se só souber estabelecer as condiçōes de verdade de algumas poucas sentenças (como ocorre com estrangeiros que não dominam uma língua), ele não sabe a língua (seja qual língua for), porque saber uma língua não é saber uma lista - como ocorre nos corretores do Word que funcionam por comparação com uma lista pré-dada -, ou só chegar ao significado da sentença na presença do correspondente estado de coisas no mundo, mas saber construir interpretaçóes. Essa intuição já está em Saussure (1916), na ideia de paradigma e sintagma. 
Quem sabe o que (es)tá choven(d)o significa sabe o que está V-ndo e chovsignificam, mas se ele sabe isso, sabe também o que está significa porque sabe que não significa esteve ou vai estar. Isso tudo e a própria noção de $\mathrm{V}$ (erbo) na descrição da perífrase já deixa claro que a língua é uma estrutura, um sistema. Mas não é um sistema fechado de oposiçōes, como pensou Saussure, embora ele fale em álgebra da língua - a tradição francesa mostrou os limites dessa concepção de estrutura fechada do estruturalismo saussuriano, explorando a ideia de negativo, de falha, de furo no sistema. Por outro viés, Chomsky mostra que a criatividade, o fato de que o indivíduo não é subjugado pelo sistema, leva à ideia de composicionalidade e de sistema recursivo. Essa já era uma ideia antiga na Lógica e nos sistemas formais, que Chomsky transpóe para a sintaxe das línguas naturais. De qualquer modo, o sistema ser aberto significa que somos criativos, interpretamos o que não está previsto, mas que é o possível da língua. Interpretamos expressões que nunca ouvimos antes.

Assim, o que esse falante sabe, sua capacidade semântica, não é apenas associar uma sentença a uma situação no mundo, mas associar uma trama de sentenças, em que há recorrências. $O$ falante sabe compor, interpretar sentenças novas. Tecnicamente, trata-se de explicitar como a composição estrutural das palavras e sintagmas em sentenças gera certas condiçōes de verdade e não outras. A semântica tem o compromisso de descrever essa capacidade que os falantes têm de atribuir condições de verdade a qualquer sentença de sua língua, mesmo uma que ele jamais tenha ouvido antes, utilizando como metalinguagem uma linguagem lógica, arregimentada, porque pretendemos que nossos cálculos sejam avaliados pelos nossos pares.

Neste artigo, vamos mostrar um pouco da história da Semântica Formal das Línguas Naturais, herdeira da Semântica Formal dos lógicos, mas que não pode ser com ela confundida. A Semântica Formal, que surgiu na Lógica e na Filosofia, não é uma ciência empírica, não tem como objetivo explicar a capacidade semântica que os falantes de uma língua têm, sua tarefa é estabelecer raciocínios válidos. Já a semântica formal das línguas naturais tem o compromisso empírico de explicar como a atribuição de significados às expressões das línguas humanas funciona. $\mathrm{O}$ compromisso da semântica formal das línguas naturais com a lógica é aquele que os cientistas têm: empreendimentos científicos devem utilizar linguagens arregimentadas, porque visam à refutação, à compreensão pública mais explícita possível. Assim, a relação da semântica formal com a 
formalização se dá porque ela pretende o rigor e a precisão típicos dos empreendimentos científicos. Essa visão instrumental da formalização deixa em aberto várias questōes de ordem metafísica: as línguas naturais são efetivamente cálculos? Os blocos primitivos de significado já são dados? São mentais? Estão no mundo? Aparecem no uso? Questôes semelhantes à pergunta: A natureza é, para os físicos, de fato, matemática? O bom de termos uma agenda para explicar é que podemos adiar essas discussões e nos deter nas línguas, que são tão fascinantes!

Vejamos esse percurso de afastamento da Lógica, e de seu objetivo explícito de verificar a validade de raciocínios, em direção às línguas naturais e sua semântica.

É curioso notar que até um certo momento a maioria dos lógicos e dos linguistas não acreditou que a lógica fosse aplicável ao estudo das línguas humanas. Para os lógicos, as línguas naturais eram (e ainda são para alguns deles) consideradas muito assistemáticas, vagas e ambíguas para que fossem passíveis de serem descritas a partir do uso linguagens lógicas. E, para alguns linguistas, as linguagens formais são estruturalmente muito diferentes das línguas humanas; por exemplo, as linguagens lógicas só admitem expressões absolutamente independentes do contexto, o que não acontece com as línguas humanas. Mas, essa diferença não impede que adaptemos o cálculo para explicar a propriedade dêitica das línguas humanas. Kaplan (1989), por exemplo, já inserido na visão de que o objetivo da semântica é entender o funcionamento de uma parte importante das línguas humanas, cria um sistema formal para explicar o funcionamento dos demonstrativos.

Assim, mesmo cercada de ceticismo (que se mostrou infundado, na maior parte das vezes), a semântica formal acabou não apenas por obter um lugar nos estudos linguísticos, mas por apresentar resultados surpreendentes que a tornam hoje uma disciplina respeitável e em efervescência.

\section{Da Semântica Lógica à Semântica Formal das Línguas Naturais}

A origem da semântica formal filosófica está na filosofia e na lógica. Numa perspectiva mais ampla, podemos dizer que a semântica formal é herdeira dos esforços de constituição de uma lógica, já na Grécia Clássica, pelos aristotélicos e pelos estóicos. Seu objetivo é construir sistemas dedutivos válidos, como 
aparece na descrição que Aristóteles faz das figuras de raciocínio (os silogismos). Numa perspectiva mais próxima temporalmente, a semântica formal descende da vertente analítica e lógica da filosofia, uma tradição que tem Frege, Russell, Carnap, Wittgenstein, Tarski, Quine, Davidson, Kripke, Hintikka e Montague, para citar apenas alguns de seus expoentes. O esforço da filosofia analítica em formalizar as línguas naturais para criar linguagens lógicas tinha como propósito inicial livrar a ciência e a matemática das armadilhas presentes na ambiguidade e na vagueza das línguas naturais. Mas, paradoxalmente, ao examinar atentamente as línguas naturais, esse movimento criou condições para o surgimento de um tipo de semântica que assumisse a tarefa de dar à semântica das línguas um tratamento formal. Não mais apenas um meio de aprimorar a pesquisa científica em outras áreas do conhecimento, o desenvolvimento de linguagens lógicas cada vez mais sofisticadas passou a incorporar mecanismos e operadores que tornaram essas linguagens cada vez mais adequadas à descrição do funcionamento complexo de aspectos das línguas naturais (como quantificadores, operadores modais e operadores temporais).

$\mathrm{Na}$ física, a investigação da natureza leva a desenvolvimentos na lógica e na matemática. As lógicas para-consistentes são um exemplo. Isso ocorre também na semântica; investigar as línguas naturais com o olhar da lógica e da matemática levou ao desenvolvimento de novas lógicas, criamos linguagens artificiais mais sofisticadas. Um caso claro é a contribuição da linguista Angelika Kratzer (KRATZER, 1977, 1979, 2012) para as lógicas modais. A investigação das línguas naturais mostra que as modalidades são graduais, ou seja, expressões como é muito possivel, é pouco possivel expressam graus de possibilidade. Essa gradação da modalidade não é captada pela lógica de mundos possíveis clássica e levou a autora a propor a semântica de ordenação, um acréscimo ao modelo clássico. No modelo clássico algo ou é necessário ou não é necessário. Não há graus de necessidade ou de possibilidade. Logo, não é possível captar a diferença entre É certo que vai chover, Vai chover de certeza, É possivel que chova, É bem possivel que chova, É dificil que chova, Provalvemente vai chover. Todos esses proferimentos expressam possibilidade ou necessidade e na Semântica de Mundos Possíveis Clássica se traduzem por um operador lógico (necessidade ou possibilidade) e a proposição chove.

Kratzer torna o sistema de mundos ordenado contextualmente. Por exemplo, imagine que estamos falando sobre o tempo e nossa intenção é indicar a nossa avaliação sobre o que irá acontecer em um local - digamos Curitiba. Para 
isso, identificamos um conjunto de mundos em que tudo se comporta como esperado - são os mundos sem acidentes e com percurso normal dos eventos e ordenamos esses mundos tendo por parâmetro sua maior ou menor normalidade. As sentenças sobre a possibilidade de chuva estão ordenadas frente a esse conjunto. Se nos mundos ideais chove, então as sentenças com de certeza e écerto colocam o mundo atual do falante mais próximo deles. É dificil, por outro lado, coloca o falante mais afastado desses mundos e, por isso, entendemos que o falante está indicando que ele acredita que não vai chover. Há muito a ser explorado nesse viés. A semântica de ordenação é um novo instrumento lógico que pode ter aplicação em outras áreas além dos modais.

No final dos anos 1960, o lógico Richard Montague - uma das figuras mais importante no surgimento da semântica formal das línguas naturais demonstra que as técnicas desenvolvidas para as linguagens formais poderiam ser aplicadas à descrição do significado nas línguas humanas. Para isso, desenvolve sistemas formais mais adequados ao tratamento das línguas naturais do que os sistemas desenvolvidos para os fins da lógica. ${ }^{1}$ Montague foi muito criticado, por lógicos e por linguistas, que não conseguiram perceber o alcance de seu trabalho: os lógicos diziam que ele complicava um sistema simples e suficiente para as tarefas da lógica e os linguistas diziam que seu sistema era simples demais para dar conta das complexidades das línguas naturais. Outros filósofos, como David Lewis, Max Cresswell e Terence Parsons, entenderam os objetivos de Montague e passaram a aplicar as técnicas desenvolvidas para as linguagens lógicas às línguas humanas, já num movimento que visa entender as línguas humanas, distanciando-se, portanto, da semântica dos lógicos que servia para definir raciocínios válidos. Há criação de novas técnicas e os sistema formais se modificam para se aproximar das línguas naturais.

Embora a agenda da semântica das línguas naturais ainda esteja em construção, nesse momento já temos que a semântica deve ter as seguintes características principais:

(i) Associação de aspectos do significado às condições de verdade das sentenças. Assim, o significado passa a ser visto como a capacidade que um falante tem de relacionar as expressões linguísticas ao que quer que seja a que elas se referem - mundo real, modelos desse mundo ou de outros mundos possíveis; 
(ii) Uma visão não-psicologista (não-mentalista) da linguagem, que adere ao postulado metodológico de que é preciso investigar o significado das sentenças das línguas naturais por meio de seu emparelhamento com as situações (reais ou virtuais) que elas descrevem; ${ }^{2}$

(iii) A centralidade metodológica do Princípio da Composicionalidade. Esse princípio tem duas faces: de um lado, ele afirma que o significado de uma expressão é resultado da combinação particular dos significados de suas partes; de outro, ele afirma que operaçôes sintáticas e construção de significados acontecem simultaneamente, em paralelo.

Enquanto Montague desenhava sua proposta semântica para os quantificadores no inglês (MONTAGUE, 1973), guiando-se pelos princípios acima, a sintaxe gerativa chomskiana vivia o auge de uma guerra entre correntes semânticas dentro do Gerativismo de então.

\section{As "guerras linguísticas" e o nascimento da semântica formal}

As chamadas "guerras linguísticas" são um conflito teórico, ocorrido entre meados dos anos 1960 e meados dos anos 1970, entre dois grupos de linguistas - ambos oriundos do gerativismo chomskiano - que se tornou um embate extremamente agressivo e intolerante. ${ }^{3}$ Os dois grupos em confronto receberam os nomes de Semântica Gerativa e Semântica Interpretativa. Os principais expoentes da Semântica Gerativa eram Paul Postal, George Lakoff, James MacCawley e John Robert Ross; e os principais expoentes da Semântica Interpretativa eram Noam Chomsky, Jerrold Katz, Ray Jackendoff e Jerry Fodor. E a questão central da disputa girava em torno de como a interpretação semântica de uma sentença deveria ser tratada pela teoria gramatical. Já estamos imersos no estudo das línguas naturais, estamos falando de um debate entre linguistas.

Para a Semântica Interpretativa, as regras sintáticas gerariam um conjunto de sentenças e um componente semântico separado que atribuiria uma interpretação semântica a cada uma delas. Como preferia Chomsky, a sintaxe teria independência da semântica e seria "central". Por outro lado, para a Semântica Gerativa, as interpretações semânticas seriam geradas diretamente pela 
gramática, como estruturas profundas, e as formas superficiais das sentenças, suas estruturas fonético / fonológicas, seriam derivadas das estruturas profundas por meio de um conjunto de transformações semântico-sintáticas. Para a realização dessa tarefa, tanto as estruturas profundas, semânticas, quanto o componente transformacional teriam que ser substancialmente mais complexos e poderosos do que o previsto por Chomsky. Além disso, a sintaxe deixava de ser "central" e passava a ser derivada da semântica.

Surgida justamente no período das "guerras linguísticas", a gramática lógica especialmente desenvolvida por Montague para o tratamento das línguas naturais (conhecida como Gramática de Montague) apresentava uma visão alternativa às teorias em "guerra". De acordo com essa gramática, sintaxe e semântica caminham paralelamente. Constituintes formados pelas regras sintáticas são simultaneamente interpretados pelas regras semânticas correspondentes. Essa terceira via pareceu atraente a alguns jovens linguistas, como Barbara Hall Partee, Emmon Bach e Robin Cooper, por exemplo, que passaram a escrever ensaios em que comparavam a gramática de Montague às propostas em guerra, mostrando as vantagens que a nova abordagem poderia trazer à investigação linguística. Em princípio incompatível com qualquer das posiçôes de confronto, a gramática de Montague satisfazia parcialmente pressupostos de cada uma delas. A adoção do Princípio da Composicionalidade, por exemplo, gera a necessidade de que a teoria linguística atribua estruturas sintáticas explícitas para cada sentença, ou seja, a teoria linguística requer um componente sintático que descreva formalmente a sintaxe das expressões (como queria a Semântica Interpretativa); nem a sintaxe, nem a semântica, no entanto, assumem qualquer "centralidade" ou autonomia (como propunham alguns defensores da Semântica Gerativa, que, em certo momento, passaram a usar os mecanismos teóricos semelhantes aos da gramática de Montague para gerar as estruturas profundas - que chegaram a ser propostos, em momentos mais extremados, como fórmulas no Cálculo Lambda). ${ }^{4}$

Embora não tenha em suas origens relações muito estreitas com a Gramática Gerativa, a semântica (na formulação de Montague) deve sua introdução e difusão na comunidade dos linguistas ao gerativismo e aos debates intensos que ali surgiam. Barbara Hall Partee tem lugar de destaque, porque, já em seus primeiros trabalhos (PARTEE, 1969, 1970, 1973, 1975), estabelece uma ponte entre Chomsky e Montague. 
O impacto de Montague virá com sua proposta para o tratamento da quantificação em inglês, publicado em 1973, intitulado The proper treatment of quantification in ordinary English, o famoso PTQ. Os quantificadores colocavam vários problemas para as propostas sintáticas daquele momento. Por exemplo, não é possível tratar a coordenação como apagamento de sintagmas idênticos. Vejamos um exemplo, mesmo que superficialmente. A sentença em (1.a) era interpretada como sendo a realização superficial do apagamento da segunda ocorrência de João. Ela é, assim, sinônima de (1.b):

(1) a. João saiu e morreu.

b. João saiu e João morreu.

Mas essa teoria faz predições incorretas para os sintagmas quantificados. Veja que (2.a) não é sinônima de (2.b):

(2) a. Algum menino saiu e morreu.

b. Algum menino saiu e algum menino morreu.

Sem entrar nos detalhes técnicos, para podermos descrever (2.a) precisamos da ideia que está em Montague de separar duas operações que Frege havia colocado junto nos quantificadores (FREGE, 1879. Ver também os textos de FREGE, 1978). Frege entendia que o quantificador realiza duas funções: por um lado, expressa uma força (que pode ser existencial, indicando que ao menos um dos elementos de um conjunto possui a propriedade do predicado, ou universal, indicando que todos os elementos do conjunto possuem a propriedade) e, por outro lado, faz a ligação de uma variável. Montague separa essas duas funções utilizando o Cálculo Lambda. Partee, por sua vez, introduz o cálculo lambda na linguística, mostrando que ele permite explicarmos a coordenação, as sentenças relativas, entre outros fenômenos das línguas naturais. Segundo Landman (conversa pessoal), a verdadeira revolução na linguística foi a introdução do Cálculo Lambda; teria sido esse o passo fundamental para o estabelecimento de uma autonomia para a Semântica Formal.

\section{A Semântica Formal}

A partir do final dos anos 1970, há uma grande expansão e diversificação dos enfoques teóricos dentro do paradigma da semântica formal e o campo se 
torna menos monolítico. A gramática de Montague pouco deve aos mecanismos teóricos gerativistas, sua sintaxe é, basicamente, a sintaxe usada pelas Gramáticas Categoriais (e não pela Gramática Gerativa) e a semântica é essencialmente idêntica à semântica dos sistemas modais desenvolvidos pelos lógicos (lógica intensional). Da mesma maneira, é interessante observar que o Princípio da Composicionalidade é compatível com diferentes tipos de teorias sintáticas e semânticas como, por exemplo, a Generalized Phrase Structure Grammar (GPSG), a Gramática Categorial, a Head-Driven Phrase Structure Grammar (HPSG), a Tree-Adjoining Grammar (TAG) e a Lexical Functional Grammar. E as técnicas semânticas introduzidas por Montague, como mostra Partee, também são compatíveis com uma Sintaxe Gerativa. Abriram-se, assim, diferentes modos de entender e estudar o significado.

Surgem também novas propostas teóricas, seja como modificaçōes na ontologia assumida pelo modelo de Montague, seja na criação de novos modelos teóricos. A linguista Irene Heim, desenvolve um modo de integrar a semântica formal à sintaxe chomskiana, substituindo o "design” da gramática de Montague que prevê o funcionamento paralelo das regras sintáticas e semânticas por um "design" que faz a interpretação de uma sentença, composicionalmente, a partir da Forma Lógica gerada pela sintaxe. Em outras palavras, Heim situa a semântica no nível da Forma Lógica e, a partir daí, a semântica procede quase que exatamente da forma prevista pela Gramática de Montague.

A partir dos trabalhos de Heim, a semântica formal passa a ser aceita como parte do modelo gerativista e passa a haver uma concordância entre a maior parte dos gerativistas de que as propostas da sintaxe devem ser avaliadas (pelo menos em parte) por sua compatibilidade com a semântica e vice-versa. Essa incorporação da semântica formal pela Gramática Gerativa não significa, no entanto, que a semântica formal deixe de existir como teoria semântica autônoma, independente da Gramática Gerativa, nem que parte dos gerativistas - Chomsky, em particular - continue cético quanto à adequação da aplicação de modelos de interpretação semântica de base lógica às sentenças da língua natural.

Com relação às modificações na ontologia, merece destaque a incorporação da noção de evento (já proposta nos anos 1960 por Donald Davidson (1968)) e de entidade plural (LINK, 1983) como entidades básicas do universo do discurso. Carlson (1977) introduz espécies na ontologia. 
Com relação aos novos modelos, merece destaque o aparecimento de teorias semânticas mais processuais que recebem o nome genérico de semânticas dinâmicas. Bons exemplos dessas teorias são a 'Discourse Representation Theory' (DRT) proposta por Hans Kamp $(1981,1993)$ e a 'File-Change Semantics' (FCS) proposta por Irene Heim (1982), modelos semânticos que propóem o tratamento de níveis mais complexos do significado - textos, em particular. $\mathrm{Na}$ DRT, o significado de uma sentença é entendido como a sua contribuição para a informação contida em um texto. Esse modo de abordar os significados, que tem origem nos trabalhos de Robert Stalnaker e David Lewis, permite o tratamento de fenômenos como a anáfora intersentencial, fenômeno que não era até então abordado pela semântica formal, já que esta tinha como sua unidade máxima de análise a sentença. As teorias de Kamp e de Heim, embora propostas a partir de quadros teóricos distintos, têm alcances descritivos muito semelhantes e, muitas vezes, são apresentadas como variantes notacionais de uma mesma proposta. O surgimento dessas teorias semânticas "do discurso" dá ensejo ao aparecimento de uma nova área de estudos denominada Pragmática Formal (ver KADMON, 2001).

Merece destaque, ainda, a revitalização da Gramática Categorial - sob o nome de Type-Logical Semantics (CARPENTER, 1997) - com substancial revisão das propostas iniciais de Kazimierz Ajdukiewicz (1935) e de Joachim Lambek (1958). Linguistas (lógicos) como Johan van Benthem, Bob Carpenter, Michael Moortgat, Mark Steedman, e Pauline Jakobson encabeçam essa revitalização.

Nos anos 1990, há uma tendência cada vez maior ao abandono da necessidade de construção de fragmentos formais interpretados em modelos como se faz para as linguagens lógicas e passa-se a uma interpretação direta nos (diferentes) mundos. Assim, a Semântica torna-se mais "davidsoniana", no sentido de abandonar uma teoria de modelos em favor de condiçóes de verdade absolutas (DAVIDSON, 1967, 1970). O distanciamento de modelos explícitos se dá concomitantemente à busca de restriçôes semânticas mais gerais que expliquem as variações entre as línguas na existência ou não de certas denotações e de certos operadores. E, como aconteceu em todas as subáreas da linguística formal, há uma tendência crescente em direção a uma diversidade maior nos tópicos e nas línguas tratadas.

Fundam-se revistas diretamente ligadas à área. Desde 1977, circula o periódico Linguistics and Philosophy, devotado ao estudo da estrutura e significado 
nas línguas naturais. Em 1982, começa a circular o Journal of Semantics; em 1993, Irene Heim e Angelika Kratzer organizam a revista Natural Language Semantics. Mais recentemente, em 2007, Kai von Fintel e David Beaver fundaram a revista virtual Semantics and Pragmatics.

\section{A Semântica Formal no Brasil.}

No Brasil, a história da Semântica Formal começa com a formação curricular do bacharelado e do mestrado em linguística da UNICAMP a partir dos anos 1970. Um dos propósitos da fundação da Unicamp era inserir o Brasil na pesquisa internacional. No caso particular da linguística, além de trazer professores do exterior, como Marcelo Dascal, proporcionou que professores em formação fossem a centros europeus de pesquisa, entre eles, Rodolfo Ilari e Carlos Franchi. Já nas primeiras propostas curriculares, o bacharelado em linguística previa disciplinas como 'Matemática para Linguistas' (dois semestres), que claramente indicavam um encaminhamento para os estudos formais. Provavelmente, essas disciplinas visavam mais os estudos de sintaxe formal, relacionados ao momento de introdução dos estudos gerativos no Brasil, mas que também serviam de base para os estudos de semântica formal.

No mestrado em Linguística, não havia a disciplina 'Semântica', mas havia uma disciplina que se ocupava do assunto e que, significativamente, se chamava 'Lógica e Linguagem' (com dois semestres). Segundo Borges Neto, sua experiência com esta disciplina foi a seguinte:

Cursei as disciplinas 'Lógica e Linguagem I' e 'Lógica e Linguagem II' em 1977. Em ambas havia uma divisão dos conteúdos em duas partes: uma introdução à lógica, ministrada pelo professor Luiz Henrique Lopes dos Santos, e uma introdução à linguística formal, ministrada pelo professor Rodolfo Ilari. No primeiro semestre, a parte lógica consistiu numa apresentação do cálculo de predicados de $1^{\text {a }}$ ordem e a parte linguística consistiu de estudos sobre a 'hierarquia de Chomsky' (gramáticas de estados finitos, gramáticas livres de contexto e sensíveis ao contexto etc.). No segundo semestre, a parte lógica consistiu numa introdução às lógicas nãoclássicas (lógica intensional, particularmente) e a parte linguística consistiu em estudos sobre fenômenos da semântica das línguas 
naturais (anáfora e quantificação). Paralelamente, em algumas aulas, lemos em conjunto o texto General Semantics de David Lewis (LEWIS, 1972). A disciplina do primeiro semestre era obrigatória, enquanto a do segundo semestre era optativa (e éramos apenas dois alunos cursando).

Além dessas disciplinas curriculares, o mestrado em Linguística da UNICAMP também previa a possibilidade de que os alunos cursassem disciplinas de outras áreas e merece destaque uma disciplina oferecida em 1976 pelo Instituto de Matemática chamada 'Gramáticas Formais' e cursada por alguns alunos do mestrado em Linguística (entre eles, Ligia Negri). A disciplina, ministrada pela professora Marta Sagastume, teve como assunto principal o famoso texto The proper treatment of quantification in ordinary English, de Richard Montague, que foi publicado pela primeira vez em 1973, e que, como já dissemos, foi fundamental na constituição da semântica formal das línguas naturais.

Os cursos de linguística da UNICAMP, quase ao mesmo tempo em que a semântica se consolidava no exterior, davam aos alunos condiçóes para acompanhar o que se fazia nos centros de pesquisa. De grande importância foi Marcelo Dascal, não apenas porque ele proporcionou a tradução dos clássicos nas diferentes áreas da linguística de ponta da época - no caso da nossa área o volume de Semântica (DASCAL, 1982) e o volume de Pragmática (DASCAL, 1982) - mas também porque ele foi o responsável pela organização de vários eventos que permitiram a presença no Brasil de pesquisadores e filósofos de vanguarda. O número 9 da Revista do Caderno de Estudos Linguísticos-CEL-, por exemplo, publicou os textos apresentados no Encontro Internacional de Filosofia da Linguagem em 1981, que se realiza na Unicamp e que teve a participação de Donald Davidson, Emmon Bach, John Searle e George Lakoff, entre outros.

Não por acaso, então, a pesquisa em semântica no Brasil acabou ocorrendo em instituições universitárias que abrigavam ex-estudantes de mestrado e doutorado dessa instituição. A saída de estudantes para cursar linguística no exterior, a partir do final dos anos 1970, trouxe pesquisadores com outras formações, mas a pesquisa em semântica no Brasil se construiu em torno de exestudantes da UNICAMP - todos ex-orientados de Rodolfo Ilari e / ou Carlos Franchi. Recentemente, em 2009, com o retorno de Ilari de seu estágio na Suécia, Edson Françozo e Renato Basso (BASSO; FRANÇOZO, 2010) organizaram um encontro de semanticistas brasileiros para conversar sobre a 
filiação de seu trabalho à pesquisa de Ilari. Nesse encontro, estavam presentes diferentes gerações de semanticistas, de Borges Neto, da primeira geração, a Quadros Gomes, já bisneta, como pode ser atestado pelo volume 52, n.2, de 2010, do Caderno de Estudos Linguísticos dedicado a esse encontro.

Houve vários eventos que permitiram esse florescimento da semântica no Brasil. De especial importância foram os Workshops, que tiveram início no final dos anos 90. A semântica formal nacional ganhou um grande impulso com a organização por Ana Müller, em 2000, do primeiro Workshop on Formal Linguistics na Universidade de São Paulo. A importância da criação dos workshops foi enorme não apenas porque permitiu que os semanticistas tivessem um fórum para discutir suas pesquisas mas também porque seu formato incluia a presença de pelo menos um pesquisador internacional de renome que sempre ministrava um minicurso. Esses pequenos cursos, em geral de 20 horas, dispersas ao longo de alguns dias, permitem nossa atualização e o estabelecimento de contato com esses pesquisadores, para a discussão dos projetos em andamento. Neste ano de 2012, o Workshop, que está em sua nona edição, será realizado em agosto, no Rio de Janeiro, e conta com a presença, entre outros, de Christopher Kennedy, da Universidade de Chicago, e de Gregory Carlson, da Universidade de Rochester, dois importantes pesquisadores da semântica formal.

Segundo Esmeralda Negrão (c.p.), os dois primeiros workshops foram coincidências felizes que permitiam integrar projetos. $\mathrm{O}$ primeiro, que se chamou "Workshop Sintagmas Nominais e Verbais Genéricos no Alemão e no Português do Brasil', ocorreu de 11 a 14 de setembro de 2000, e se centrou nas pesquisas sobre a genericidade realizadas pelo então professor visitante na USP, H. Blüdhorn, para o alemão, e, por Müller, para o português brasileiro. A palestrante convidada foi Angelika Kratzer. No segundo, Carlos Mioto havia convidado Luigi Rizzi e Adriana Beletti, ambos professores da Universidade de Siena, para uma série de seminários em Florianópolis e eles foram os palestrantes do "II Workshop on Formal Linguistics at USP: Syntax and Semantics", nos dias 23 e 24 de agosto de 2001. Para esse encontro a palestrante para a semântica foi Barbara Partee. O terceiro workshop já não foi mais uma coincidência. Maria José Foltran recorda uma conversa, durante o $50^{\circ} \mathrm{GEL}$, realizado na Universidade de São Paulo, em 2001, em homenagem a Carlos Franchi, que com Ana Müller e Roberta Pires de Oliveira decidimos oficializar os workshops. Estava fundada a tradição dos workshops que já trouxeram para o Brasil, Angelika Kratzer, Irene 
Heim, Tim Stowell, Lisa Selkrik, Kai Von Fintel, Veneta Dayal, Susan Rothstein, Paul Pietrovsky e Yael Sharvit. Montava-se ali também uma parceria que seria muito frutífera, ligando São Paulo (USP), Curitiba (UFPR) e Florianópolis (UFSC). É importante destacar que boa parte dos trabalhos dos semanticistas formais vem sendo publicada na Revista Letras, publicada pela UFPR desde 1953: textos apresentados nos vários workshops vêm sendo publicados na forma de "dossiês".

Paralelamente aos workshops, inspirados em parte por uma reunião em 1999 em Curitiba, houve vários movimentos para integrar a semântica formal na pesquisa nacional. Como relata Roberta Pires de Oliveira, naquela reunião, em que estiveram presentes Rodolfo Ilari, Ana Müller, José Borges Neto, Maria José Foltran, Márcio Guimarães, entre outros, houve o reconhecimento de um grupo com interesses semelhantes: a descrição semântica das línguas naturais a partir do ponto de vista formal. As participaçôes em congressos nacionais se intensificaram. Talvez a primeira publicação em semântica formal no Brasil tenha sido a pequena introdução realizada por Ilari e Geraldi (1991), mas foi após esse encontro que as publicações ganharam relevo: o manual de Pires de Oliveira (2001), a publicação da tradução de Chierchia (2003), realizada por Ilari, Pagani e Negri, a coletânea de artigos organizada por Müller, Negrão e Foltran (2003), entre outros que se seguiram. Durante esse período, o grupo de ex-alunos formou uma nova geração de alunos, da iniciação científica até o doutorado.

Os anos 2000 conheceram uma maior integração nacional e a formação de centros em São Paulo, Florianópolis, Curitiba, e em Belo Horizonte, com a pesquisa de Márcia Cançado, na UFMG, sobre papéis temáticos, que hoje é desenvolvida também com Foltran e Wachowicz da UFPR. Formou-se o grupo de pesquisa sobre Quantificação nas Línguas Naturais, liderado por Roberta Pires de Oliveira e Ana Müller. Começaram também as parcerias internacionais, tanto pelo lado do estudo das línguas indígenas, com Müller e Storto, quanto para o português brasileiro, por meio do Projeto de Cooperação Internacional Capes-Cofecub "Os Nominais Nus no Português Brasileiro: a interface sintaxesemântica”, coordenado por Pires de Oliveira no Brasil e Carmen Dobrovie-Sorin (Paris 7, CNRS) na França. Há ainda uma cooperação em andamento com Israel, de que participam Susan Rothstein, Fred Landman e Edit Doron, e uma cooperação sendo construída com a Holanda.

A Semântica Formal ganhou nesses anos um lugar de respeito na pesquisa nacional em linguística e dá seus primeiros passos internacionais, participando 
assim desse amplo projeto que é compreendermos a capacidade humana de interpretar qualquer sentença de sua língua. A existência de uma solicitação para redigirmos uma história da semântica formal comprova que a semântica formal é uma área consolidada dentro da linguística brasileira.

\section{Tendências}

Podemos perceber atualmente uma maior integração da Semântica Formal com outras áreas da linguística formal, como também com outras áreas do saber. Surge, consequentemente, a necessidade de pesquisas em equipes multidiciplinares. Partee (2011) fala do crescimento do conteúdo empírico que colocou novas questóes para a área. A capacidade semântica é certamente universal (biológica?), todos temos essa capacidade independentemente do saber escolar, mas como seria esse sistema em cada língua em particular? Há universais semânticos? Como eles seriam? Cresce a necessidade de verificação de hipóteses de pesquisa, o que leva, por um lado, a um crescente interesse na investigação de línguas relativamente menos estudadas, como o russo, o português brasileiro, as línguas indígenas ou as línguas de sinais, e, por outro, a experimentos, em particular, experimentos psicolinguísticos, e às pesquisas em corpora.

$\mathrm{O}$ evento chamado Semantics of Under-Represented Languages in the Americas - SULA -, que teve seu primeiro encontro em 2001, na University of Massachusetts at Amherst, exemplifica esse movimento em direção às línguas pouco representadas nos estudos teóricos. $\mathrm{O}$ encontro impõe uma abertura teórica, no sentido de que desloca o eixo da linguística do inglês em direção a outras línguas. Será que olhar o inglês pelo prisma de uma língua não indoeuropéia como o Karitiana não produziria teorias melhores? Nessa direção, caminham, no Brasil, as pesquisas de Müller (ver MÜLLER; BERTUCCI, 2012, entre outros), e de Storto (2012), por exemplo. A descrição formal dessas línguas pouco estudadas implica a preocupação com o desenvolvimento de técnicas de trabalho de campo para investigação de fenômenos semânticos, como os que têm sido desenvolvidos por Matthewson (2004) para a coleta de dados semânticos.

Há muita pesquisa a ser realizada com as línguas ainda pouco estudadas e esses estudos só se conectam à medida que buscamos explicar as variaçôes por meio das línguas, buscamos generalizaçōes translinguísticas. Essas pesquisas só podem ser feitas em equipes. Um exemplo dessa busca de explicação da variação 
na semântica é o parâmetro semântico proposto por Chierchia (1998). Chierchia propõe que há três tipos de línguas no mundo, tendo em vista se essas línguas admitem ou não nominais nus em posições de argumento. Por exemplo, o chinês diz:

(3) Wo mai-leshu le.

eu comprar-Perf livro $\operatorname{Prt}^{5}$

'Eu comprei um livro/alguns livros/o(s) livro(s).

(retirado de Kurafuji (2004), exemplo (1))

Que traduzido palavra a palavra para o português, nos dá:

(4) Eu comprei livro.

Em (4), livro é um exemplo de um nominal nu em posição argumental. Mas o português não é como o chinês ou como o karitiana (ver MÜLLER et al., 2006), porque temos também o artigo definido (o livro), o indefinido (um livro), entre outras possibilidades (algum livro, por exemplo). O português brasileiro é uma língua mais semelhante ao inglês, porque temos todas essas possibilidades. Mas, ao mesmo tempo, o português brasileiro não é como o inglês, porque só nós temos o famoso singular nu, exemplificado acima, que levou, no Brasil, a uma proposta de reformulação do parâmetro semântico de Chierchia (ver MÜLLER; OLIVEIRA, 2004 e PIRES DE OLIVEIRA, 2012), entre outros).

Da mesma maneira, a referência crescente a dados experimentais, vindos de estudos de aquisição ou de experimentos psicolinguísticos exige a elaboração de pontes entre o trabalho teórico - de natureza "não-mentalista" - com os fatos de natureza mental / cerebral. Há já alguma pesquisa nessa direção no Brasil, a pesquisa sobre os advérbios duracionais de Basso (2007) e a pesquisa de Wachowicz (2011) sobre aspecto e nominais, são exemplos. Cresce também o interesse pelos bancos de dados, pelas ocorrências, e com o dado negativo gerado pela introspecção. Um exemplo desse tipo de abordagem aparece na pesquisa de Wall (2012), sobre a possibilidade de termos o singular nu em relação paradigmática, por assim dizer, com o sintagma nominal, em casos como:

(5) o carro do moleque num tinha documen::to [...] documento tava na chá::cara.

(exemplo 5 de WALL, 2012, retirado de IBORUNA: AC-079) 
Note que a segunda ocorrência de documento em (5) é definida, específica e familiar. Ocorrências como essa, atestadas em corpora, levantam vários questionamentos sobre certas análises sobre o singular nu como sintagmas indefinidos, por exemplo. Colocam também a questão de qual seria o lugar do dado marginal na pesquisa em semântica.

$\mathrm{Na}$ Semântica Formal, a introspecção é fundamental para elaborarmos o dado negativo, aquilo que não produzimos e que, portanto, pode nos ajudar a entender como é o sistema de uma língua. Por exemplo, não dizemos, como vimos, algum, mas dizemos todo $o$. Essas intuiçôes sobre se uma dada sequência é ou não aceita pelos falantes podem ser medidas. Ionin e Grolla (2011) tratam, por exemplo, da diferença de comportamento entre falantes de inglês e falantes de português quanto ao uso dos nominais nus. Falantes de inglês falam português utilizando o plural nu. Eles dizem Mulheres no Brasil são lindas. Sem dúvida, também dizemos isso, mas dizemos mais informalmente Mulher no Brasil é linda. Falantes do inglês não usam o singular nu, enquanto os falantes do português brasileiro usam o singular nu quando falam inglês, produzindo sentenças que são agramaticais no inglês padrão Woman talks a lot! (Mulher fala muito!). Há muitas questôes a serem exploradas por essa vertente experimental.

Com essa crescente aproximação com trabalhos mais empíricos, como o trabalho de campo e os experimentos psicolinguísticos, aumenta a consciência de que dados sobre a semântica das línguas são altamente sensíveis ao contexto. Assim, observa-se o uso cada vez mais frequente de contextualização dos dados apresentados, seja sob a forma de minidiscursos, seja pela descrição do contexto em que eles ocorreram. Junto a isso, observa-se também uma maior sensibilidade às diferenças entre língua falada e língua escrita e ao significado da prosódia, o que requer investigações mais profundas das interfaces e das modalidades de comunicação. Nessa direção, há, no Brasil, as pesquisas de Sérgio Menuzzi e Maria Cristina Figueiredo e Silva, entre outros. Seara e Pires de Oliveira (no prelo) mostram, por exemplo, que a prosódia guia a interpretação de sequências que geram mais de uma interpretação, como em Maria não está grávida de novo. Os experimentos com prosódia mostraram que os falantes associam a cada interpretação uma curva prosódica. Mais uma vez, há muito a ser estudado sobre essa questão, em particular: qual é a relação entre a prosódia e a semântica?

Outra tendência observada é a aplicação dos modelos formais usados em semântica a fenômenos da pragmática, do discurso e do diálogo. Novamente, 
há aqui pontes com a Fonologia, os padrões entoacionais, as Teorias de Informação e com a já mencionada Pragmática Formal e alguns modelos formais do diálogo. A literatura já conta com trabalhos sofisticados para o inglês, por exemplo, a pesquisa de Potts (2005) sobre as implicaturas convencionais de Grice que, na sua redefinição, inclui apenas expressões que marcam a presença subjetiva do falante, como a expressão merda em Desliga essa merda de TV! Esse é um caminho que ainda não apareceu no Brasil.

A investigação de novas ferramentas formais e a importação consistente de ferramentas da matemática, da computação e da estatística, diante desses novos desafios, apresenta-se como uma área de estudos com grande potencial de crescimento. A linguística computacional faz parceria com a semântica em dois lugares: como ferramenta de auxílio na busca e análise em bancos de dados e na implementação de teorias semânticas. Suponha, por exemplo, que queiramos entender porque a distinção semântica presente no português brasileiro atual entre as duas construções todo o $N$ e todo $N$ desapareceu no português europeu contemporâneo, em que só há uma forma todo o $N$ que expressa os dois significados. Esse tipo de pesquisa sobre a história de uma certa construção ficaria muito mais fácil se tivéssemos um corpus etiquetado e a linguística computacional como auxílio. Como a semântica formal se pretende preditiva e busca ser absolutamente explícita, deverá ser possível implementar computacionalmente as suas propostas e, assim, verificar o seu alcance teórico. No Brasil, essa vertente é ainda pouco explorada, mas aparece na pesquisa de Borges Neto e Pagani (2010, por exemplo. Ver também PAGANI, 2007, 2011 e LIMA, 2002).

Ainda muito incipiente, inicia-se uma linha de pesquisa na história desse tipo de semântica de línguas específicas. Essa pesquisa, pioneira, começa a ser desenvolvida no Brasil pelo grupo coordenado por Ilari (2011) e Luis Passegi (professor da UFRN). Nesse quadro teórico, é possível, por exemplo, estudarmos a mudança na grade temática dos verbos. Por exemplo, o verbo esquecer vem do verbo latino cadere, e podemos imaginar que se representava o esquecimento como uma queda: as coisas caem no esquecimento. Com essa significação, harmonizava-se naturalmente uma diátese em que o sujeito era a coisa esquecida e em que a pessoa desmemoriada era um beneficiário (ou talvez alguém prejudicado pelo esquecimento). Isso explica que a regência tradicional de esquecer fosse com um dativo: "esqueceu-me o nome dessa pessoa", que, em seguida, serviu de modelo para "não me lembra o nome dessa pessoa" (essas 
regências são as preferidas de Machado de Assis). Hoje, as regências correntes

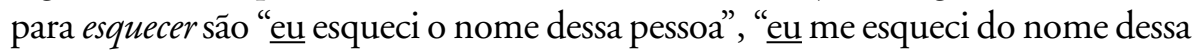
pessoa"; nessas regências mais atuais, o ser humano em que se passa o esquecimento deixa de ser um beneficiário, e isso pode certamente ser visto como um sintoma de que ninguém mais reconhece no verbo esquecer um verbo que já indicou uma queda.

Apesar desse florescimento nacional e internacional da semântica formal, da abrangência de seus estudos, essa é ainda uma das áreas da linguística que conta com poucos pesquisadores no Brasil, mas que está em crescimento. Embora, como vimos, sua história seja já relativamente longa nos meios acadêmicos brasileiros, data dos anos 70 , sua difusão é ainda restrita. Talvez a exigência de raciocínio formal, de conhecimentos de lógica e certa familiaridade com a manipulação de formalismos, muitas vezes distantes da formação oferecida por nossos cursos de Letras, afaste os estudantes desse tipo de estudo, talvez uma tradição dicotômica que separa o estudo das línguas do estudo da matemática e da lógica, talvez uma compreensão equivocada de que a linguagem humana não é passível de ser descrita por meio de um formalismo lógico - ou mesmo estudada cientificamente - criem um ambiente menos favorável a seu crescimento no Brasil. Como bem lembrou Márcio Guimarães no famoso encontro em 1999 em Curitiba, há um grande preconceito contra a Semântica Formal, contra os formalistas de qualquer tendência.

\section{Notas}

${ }^{1}$ Montague desenvolve, em sequência, três sistemas. Ver MONTAGUE, 1970a, 1970b e 1973. O mais conhecido pelos linguistas é o sistema de 1973 (conhecido como PTQ).

${ }^{2}$ Esta postura não é contraditória com a ideia de que o que se quer explicar é o mecanismo interno que possibilita que o falante interprete sentenças, pois essa interpretação é que relaciona a linguagem e as coisas sobre as quais ela fala (o mundo / os mundos).

${ }^{3}$ O termo "guerras linguísticas" vem do título do livro de Harris (1993) e se tornou de uso generalizado para a caracterização desse período da linguística norte-americana. 
${ }^{4}$ O Cálculo Lambda é um sistema lógico-matemático relacionado à Teoria das Funções, criado por Alonzo Church nos anos 1930 para dar conta do funcionamento das variáveis (ligação e substituição) nas fórmulas lógicas. Com grande aplicação na ciência da computação e na matemática, esse cálculo permite o desenvolvimento de uma semântica simples para as computações.

${ }^{5}$ Per: perfectivo; Prt: pretérito.

\section{Referências}

AJDUKIEWICZ, K. 1935. Die syntaktische Konnexität. Studia Philosophica 1, p. 127 (tradução para o português de José Borges Neto e Ligia Negri: "A conexidade sintática" em <http://people.ufpr.br/-borges/publicacoes/traducoes/ajdukiewicz.pdf)>.

BASSO, R. Telicidade e detelicização: semântica e pragmática do domínio tempoaspectual. 2007. Dissertação (Mestrado) - Unicamp, 2007.

BASSO, R.; FRANÇOSO, E. Apresentação - Rodolfo Ilari, a semântica e o pensamento analítico em linguística. Cadernos de Estudos Linguísticos, v. 52, n. 2, 2010.

BORGES NETO, J.; PAGANI, L. A. A interpretação dos prossintagmas. Cadernos de Estudos Lingüisticos, v. 52, n. 2, p. 255-283, 2010.

CARLSON, G. Reference to Kinds in English. 1977. Ph.D. Dissertation, Amherst: University of Massachusetts (publicado, com o mesmo título, em 1980, pela editora Garland, Nova Iorque).

CARPENTER, B. Type-Logical Semantics. Cambridge, Mass.: MIT Press, 1997.

CHIERCHIA, G. 1997. Semantica. Bologna: Il Mulino (tradução para o português de Luis Arthur Pagani, Ligia Negri e Rodolfo Ilari: Semântica, Campinas e Londrina: Editora da Unicamp e Editora da UEL, 2003).

CHIERCHIA, G. Reference to kinds across languages. Natural Language Semantics, v. 6, n. 4, p. 339-405, 1998.

CHOMSKY, N. Logical syntax and semantics: their linguistic relevance. Language 31, p. 36-45, 1955.

CHOMSKY, N. Rules and Representations. Oxford: Blackwell, 1980. (tradução para o português de Marilda Averbug, Paulo Henriques Britto e Regina Bustamente: Regras e Representaçôes. Rio de Janeiro: Zahar, 1981).

CHOMSKY, N. The Generative Enterprise: A Discussion with Riny Huibreghts and Henk van Riemsdijk. Dordrecht: Foris, 1982. 
CHOMSKY, N. On formalization and formal linguistics. Natural Language and Linguistic Theory 8, p. 143-147, 1990.

DASCAL, M. (Org.). Fundamentos Metodológicos da Linguística. Volume III Semântica. Edição financiada pelo organizador com a colaboração de professores e alunos do IEL, Unicamp, 1982.

DASCAL, M. (Org.). Fundamentos Metodológicos da Linguística. Volume IV Pragmática. Edição financiada pelo organizador com a colaboração de professores e alunos do IEL, Unicamp, 1982.

DAVIDSON, D. Truth and Meaning. Synthèse, v. 17, p. 304-323, 1967.

DAVIDSON, D. The logical form of action sentences. In: n. RESCHER (Ed.). The Logic of Decision and Action. Pittsburgh: University of Pittsburgh Press, 1968. p. 81-95.

DAVIDSON, D. Semantics for natural language. In: VISENTINI, B. et al. (Ed.). Linguaggi nella società e nella tecnica. Milan: Edizioni de Communità, 1970. p. 177-188.

FREGE, G. Begriffschrift. Halle: L. Nebert, 1879.

FREGE, G. Lógica e Filosofia da Linguagem. São Paulo: Cultrix/EDUSP, 1978. (Coletânea de textos selecionados e traduzidos por Paulo Alcoforado).

HARRIS, R. A. The Linguistic Wars. Oxford: Oxford University Press, 1993.

HEIM, I. The semantics of definite and indefinite noun phrases. 1982. $\mathrm{PhD}$ Dissertation. University of Amherst, 1982. Publicado em 1989.

ILARI, R. O Projeto de Natal, 2011. Manuscrito.

ILARI, R.; GERALDI, J. W. Semântica. São Paulo: Ática, 1991.

ILARI, R.; BASSO, R. O Português da Gente. São Paulo: Contexto, 2006.

IONIN, T.; GROLLA, E. Nominal interpretation by native and non-native speakers of Brazilian Portuguese. Third International Conference on Bare Nominals: Theory and Experiments. Universidade Federal do Rio de Janeiro, 2011.

KADMON, N. Formal Pragmatics - Semantics, Pragmatics, Presupposition, and Focus. Oxford: Blackwell, 2001.

KAMP, H. A theory of truth and semantic representation. In: GROENENDIJK, J. et al. (Ed.). Formal Methods in the Study of Language. Amsterdam: Mathematical Centre, 1981. p. 277-322 (republicado em GROENENDIJK, J; JANSSEN, T.; STOKHOF, M. (Ed.). Truth, Interpretation and Information. Dordrecht: Foris, 1984. p. 1-41). 
KAMP, H; REYLE, U. From Discourse to Logic: introduction to Model Theoretic Semantics of Natural Language, Formal Logic, and Discourse Representation Theory. Dordrecht: Kluwer, 1993.

KAPLAN, D. Demonstratives. In: ALMOG, J.; PERRY, J.; WETTSTEIN, H. (Ed.). Themes from Kaplan. Oxford: Oxford University Press, 1989.

KRATZER, A. What 'must' and 'can' must and can mean. Linguistics and Philosophy 1, p. 337-355, 1977.

KRATZER, A. Conditional necessity and possibility. In Bauerle, R.; Egli, U.; von Stechow, A. (Ed.). Semantics from Different Points of View. Berlin: Springer-Verlag, 1979. p. 117-147.

KRATZER, A. Modals and Conditionals. Oxford: Oxford University Press, 2012.

KURAFUJI, Takeo. Plural morphemes, Definiteness, and the notion of Semantic Parameter. Language and Linguistics, v. 5, n. 1, p. 211-242, 2004.

LAMBEK, J. The Mathematics of Sentence Structure. American Mathematical Monthly, v. 65, p. 154-169, 1958.

LEWIS, D. General Semantics. In: HARMAN, G; DAVIDSON, D. (Ed.). Semantics of Natural Languages. Dordrecht: Reidel, 1972. p. 169-208.

LIMA, T. S. Interpretação semântica do objeto nulo no português do Brasil. 2002. Dissertação (Mestrado em Informática) - UFPR, 2002. (Orientador: Michel Gagnon; co-orientador: José Borges Neto).

LINK, G. The logical analysis of plurals and mass terms: a lattice-theoretic approach. In: BAUERLE, R.; SHWARTZE, C; von STECHOW, A. (Ed.). Meaning, Use and Interpretation of Language. Berlin: Walter de Gruyer, 1983. p. 302-323.

MATTHEWSON, Lisa. On the Methodology of Semantic Fieldwork. International Journal of American Linguistics, v. 70, p. 369-415, 2004.

MONTAGUE, R. 1970a. English as a formal language. In: VISENTINI, B. et al. (Ed.). Linguaggi nella Societá e nella Tecnica, Milão: Edizioni di Comunitá, 1970a. p. 189-224 (recolhido em THOMASON, R. (Ed.). 1974, p. 188-221).

MONTAGUE, R. 1970b. Universal Grammar. Theoria 36, p. 373-398, 1970 b. (recolhido em THOMASON, R. (Ed.). 1974, p.222-246).

MONTAGUE, R. The proper treatment of quantification in ordinary English. In: HINTIKKA, J.; MORAVCSIK, J.; SUPPES, P. (Ed.). Approaches to Natural Language. Dordrecht: Reidel, 1973. p. 221-242 (recolhido em THOMASON, R. (Ed.). 1974, p. 247-270). 
MÜlleR, A. L.; NEGRÃO, E. V.; FOLTRAN, M. J. (Org.). Semântica formal. São Paulo: Contexto, 2003.

MÜLLER, Ana; BERTUCCI, Roberlei. Sintagmas nominais nus expressam a distinção definido vs indefinido? O caso do karitiana. In: PIRES DE OLIVEIRA, Roberta; MEZARI, Meiry Peruchi (Org.). Nominais Nus. Um olhar através das linguas. Campinas, Mercado de Letras, 2012. p. 149-180

MÜLLER, Ana; OLIVEIRA, F. Bare Nominals and Number in Brazilian and European Portuguese. Journal of Portuguese Linguistics, Portugal, v. 3, n. 1, p. 9-36, 2004.

MÜLLER, Ana; STORTO, L.; COUTINHO-SILVA, T. Número e a distinção contável-massivo em Karitiana. Revista da ABRALIN, 2006.

PAGANI, L. A. Demonstrando uma intuição equivocada: o uso da lógica e da computação na linguística. Revista Letras v. 71, p. 11-29, 2007.

PAGANI, L. A. Representação semântica em analisadores gramaticais. Revista da ABRALIN, v. 10, p. 61-85, 2011.

PARTEE, B. H. (em colaboração com S. Ginsburg). A mathematical model of transformational grammars. Information and Control, v. 15, p. 297-334, 1969.

PARTEE, B. H. Negation, conjunction, and quantifiers: syntax vs. semantics. Foundations of Language, v. 6, p. 153-165, 1970.

PARTEE, B. H. Some transformational extensions of Montague grammar. Journal of Philosophical Logic, v. 2, p. 509-534, 1973.

PARTEE, B. H. Montague grammar and transformational grammar. Linguistic Inquiry, v. 6, n. 2, p. 203-300, 1975.

PARTEE, B. H. Is this a good time for formal semantics? Disponível em: <http:// vimeo.com/20664367>, 2011.

PIRES DE OLIVEIRA, R. Semântica Formal - uma breve introdução. Campinas: Mercado de Letras, 2001.

PIRES DE OLIVEIRA, R. A linguística sem Chomsky e o método negativo. Revista Virtual de Estudos da Linguagem, v.8, 2010.

PIRES DE OLIVEIRA, R. Parâmetro Lexical: contagem e espécie. Projeto de Pósdoutoramento, 2012. (manuscrito).

POTTS, C. The Logic of Conventional Implicatures. Oxford: Oxford University Press, 2005. 
SAUSSURE, F. de 1916. Cours de Linguistique Générale. Paris: Payot (tradução para o português de Antônio Chelini, José Paulo Paes e Izidoro Blikstein: Curso de Lingüistica Geral. São Paulo: Cultrix, 1970).

SEARA, Isabel; OLIVEIRA, Roberta Pires de. Semântica ou pragmática? Um experimento em prosódia. In: TAVEIRA DA CRUZ, Ronald (Org.). Interfaces da gramática. Curitiba: Editora CRV. (No prelo)

STORTO, L. Duplicação em Karitiana. In: PIRES DE OLIVEIRA, Roberta; MEZARI, Meiry Peruchi (Org.). Nominais Nus. Um olhar através das linguas. Campinas, Mercado de Letras, 2012. p. 213-234.

THOMASON, R. (Ed.). Formal Philosophy: Selected Papers of Richard Montague. New Haven: Yale University Press, 1974.

WALL, A. The distribution of specific and definite bare nominals in Brazilian Portuguese. In: KABATEK, Johannes; WALL, Albert (Org.). Bare Noun Phrases in Romance: theory and (empirical) data. John Benjamins, 2012. No prelo.

WACHOWICZ, T. C. Término, Léxico e Quantificação. Revista Letras, Curitiba, v. 81, p. 3, 2011. 